I employed white of egg. The eggs must be quite fresh, and should be boiled in a unitorm manner. The best way is to boil the water first, then put the eggs in altogether and let them boil for ten minutes. If a shorter time be allowed, it will be seen that the white will not separate from the yelk nicely and cleanly. It will be found that on an average fifteen eggs yield 7000 grains of coagulated albumen, or perhaps a little less. Much depends on the state of subdivision of the white of egg. An attempt to obtain uniformity was made by pounding up together the whole mass after the removal of the membrane and yelk, and then rubbing it through a No. 30 sieve. This seemed to answer well, for when suspended in water and examined the particles were found to be uniform both in shape and size. The next question was the strength of the acid, and here again, following Dowdeswell, it was determined to use distilled water acidulated with 1 per cent. hydrochloric acid of sp. gr. 1150. The specific gravity of the acid was ascertained in the ordinary way by a Westphal's balance, the observation being made at $15^{\circ} \mathrm{C}$. The necessity for having beakers of the same size and shape was fully recognised, and the mixture was constantly stirred. The observations were made at a temperature of $38^{\circ} \mathrm{C} .\left(100 \cdot 4^{\circ} \mathrm{F}\right.$. $)$, that being approximately the temperature of the body. The beakers were maintained at a uniform temperature by placing them in a water-bath with a littie jet of gas beneath. It was not thought necessary to use a gas regulator, as the themometer was carefully and constantly watched, and never varied more than a degree, or at the most a degree and a half. The test proposed was the quantity of coagulated white of egg digested by one grain of pepsin in four hours in eight ounces of 1 per cent. hydrochloric acid at a temperature of $38^{\circ} \mathrm{C}$. It was thought that the activity of each preparation could be ascertained by filtering the liquid left at the expiration of the time selected, and then, after drying, weighing the residue left on the filter. The whole experiment was a failure, for the simple reason that what was left would not filter : the fluid positively declined to be filtered. It was put on the filtering-paper, and there it remained, hardly a drop passing through, even after standing twenty-four hours. It was not hurried in any way; it was allowed to take its own time about it, but the result was always the same. Different kinds of filteringpaper were tried, and an attempt was made to humour it by folding the papers in various fantastic devices, but it was all to no purpose, and it refused to budge a drop. Finally glass-wool was experimented with, but it would not even go through that, and the whole thing had to be abandoned in disgust.

This plan having failed, another, or rather a modification of the former, was adopted. The white of egg, instead of being passed through a sieve, was cut up by hand into long narrow, thin slips or slices. These pieces were not absolutely uniform either in shape or size, but as fifteen eggs were operated on at a time, and the whole mass was mixed up together, the error arising from this source could not have been very great. The weight of albumen taken for each observation was 1000 grains, as usual. The fluid was eight ounces of 1 per cent. hydrochloric acid of sp. gr. 1-150. The temperature was $38^{\circ} \mathrm{C}$.; and the quantity of pepsin employed was one grain of each of the solid preparations and ten grains of those which were liquid. The observations in each case lasted for four hours. At the end of that time the liquid was filtered through muslin and carefully washed for thirty minutes with a small jet of distilled water. The muslin was then spread out on porous paper to absorb the excess of moisture, and allowed to remain exposed to the air at a temperature of $60^{\circ} \mathrm{F}$. for twenty-four hours. The albumen was scraped off the muslin and carefully weighed. The figure so obtained was subtracted from the weight originally taken, and in this way the quantity of albumen dissolved by one grain of each preparation was ascertained.

Thirteen solid specimens of pepsin were examined, some of English, others of French, German, or American manufacture. They were all active, but in many the proteolytic power was very small. Only four would have come up to the standard of the new British Pharmacopoeia. The name is evidently no guarantee of purity, for a specimen made by a well-known firm was represented by the figure 871, whilst another, sold under an equally well known name, had to be satisfied with an award of 162, a state of affairs which is hardly satisfactory. The same pepsin is often sold under different names, according to the amount of impurity added. I have before me a table showing the exact quantity dissolved by one grain of all the best-known pepsins, but $I$ do not think it would serve any useful purpose to publish it. Better by far that every medical man should make his own observations and form his own opinion. It may be doubted if the Pharmacopoial description of pepsin as "a light yellowish-brown powder" is a happy one, for the most active specimen was a preparation in scales. The pepsin usually supplied to hospitals is, I am sorry to say, of poor quality. In addition to the thirteen solid pepsins, I examined six liquid preparations, wines, essences, \&c., and although ten grains were taken instead of one, the results were unsatisfactory, and the only conclusion I could arrive at was that they were not very reliable, although none of them were absolutely inactive. Having used the carica papaya largely in the treatment of various forms of dyspepsia, I determined to try it against the best pepsins, but found that under the conditions already indicated it was decidedly inferior in activity. I examined in all six specimens of papaw obtained trom trustworthy sources, but only two would have come up to the Pharmacopœia test. The best papain had about half the activity of the best pepsin. I do not say that in alkaline or neutral media the papains are not more active, but simply that, tested against the best pepsins and by the same methods, they do not give equally good results. Even in a neutral solution the best papain was not equal to the best pepsin in an acid solution. A papaw preparation which in a certain time dissolved 420 grains in an acid solution dissolved 476 grains in a $\frac{1}{4}$ per cent. carbonate of soda solution and 535 grains in a neutral solution.

No one can doubt that pepsin is a valuable therapeutic agent, and that it is of the greatest possible use in the treatment of many forms of atonic dyspepsia, flatulence, and gastralgia; but to obtain anything like good results it must be given in doses very much larger than those recommended in the British Pharmacopœia. To give only from two to five grains at a time is a palpable absurdity. The reason that such good results are obtained with pepsin in the treatment of infantile diarrhoea is that it is given in proportionately larger doses. To obtain good results in the treatment of dyspepsia two things are essential-first to test your pepsin, and then to give plenty of it.

Weymouth-street, $w$.

\section{PERFORATING ULCER OF THE INTESTINE.}

BY JAMES OLIVER, M.B. ED., M.R.C.P. LOND, ASSTSTANT-PHYSICTAN TO THE HOSPITAI FOR WOMEN.

Perforating ulcer of the intestine is essentially an acute disease, depending as it does upon a localised softening and disintegration of tissue resulting from a plugging of those vessels which run in and nourish the coats of this viscus. Although from the length of time the symptoms may continue, and because of a proneness of the ulcer for some reason or other to recur, the disease may be worthy of the appellation of "chronic," yet, according to the extent and completeness of the occlusion, so the necrotic change begins to show itself in one or all of the coverings, except the serous, almost immediately they become deprived of their sole source of nutrition. The branches of the mesenteric artery pass round the sides of the intestine under the serous coat, and frequently anastomose with each other towards the free border of the gut. They subdivide and ramify in the muscular coat, supplying it with blnod, and finally end in a fine capillary network in the mucous membrane and its underlying areolar tissue. If the blood-supply to any tissue of the body be suddenly withdrawn, as happens when a vessel becomes occluded either by an embolus or a thrombus, and collateral circulation be not readily established, death of the part is inevitable. In the brain and spinal cord localised patches of softening may frequently be detected, the result of plugging of the vessels. By the introduction of emboli into the mesenteric arteries we can produce, artificially, perforations more or less complete, corresponding exactly with those ulcers now under consideration. It is therefore evident that the withdrawal of blood from a part can at least produce destruction of tissue apart from any suppurative or inflammatory change. Here the whole destructive process is truly analogous with that of dry gangrene occasionally seen in 
the extremities of the aged, where the vessels, because of degenerative changes in their coats, become impervious. Collateral circulation, however, is so readily established in the mesenteric vessels, that emboli, unless very complete, can but rarely exert any influence in the production of intestinal ulcer, except as affording a focus for coagulation of blood and the subsequent development of a thrombus. I am inclined to think that deterioration of blood and degenerative changes occurring in the protoplasm of the capillary wall favour the formation of thrombi, and are therefore potent agents in the production of intestinal ulcer. In some cases it is quite possible the cause may be thrombosis, the result of a local phlebitis. Like gastric ulcer, it so far appears to be more common in females than males. Its exciting cause is wholly unknown.

Perforating ulcer is by no means rare. It may occupy any part of the intestinal tract. Most usually it will be found, however, mid-way between the attached and free border of the gut. As a rule, two or three ulcers are to be detected situated close together or at some little distance from each other. They are generally round, but they may be irregular and even somewhat serpiginous in shape. If the perforation be complete, the serous coat usually gives way by rupturing, whilst all the other structures will be found to have necrosed to an equal extent throughout; the muscular coat, however, retracts, and a partial prolapse, so to speak, of the apparently redundant mucous membrane results. One or all of the coats may gradually disappear, the destructive process progressing from within outwards. Recovery may take place at any stage, the loss of tissue being replaced by an exudation and proliferation of cells, which eventually develop new fibrous tissue with a marked proneness to retract, producing a cicatrix of variable shape and size. The affected part of intestine may by a local peritonitis become glued to another part of the bowel or to some other abdominal or pelvic xiscus, and the perforation becoming complete, a fistulous communication may in the course of time be established. If the posterior part of the ascending or the descending colon becomes thus completely ulcerated fæcal extravasation will take place into the underlying areolar tissue outside the peritoneal cavity, and with due care the case may be brought to a favourable termination. It is but seldom that a vessel of any importance gives way producing serious hæmorrhage.

The symptoms of ulcer of the intestine are usually very insidious, and the first intimation of the presence of such a grave condition may be the sudden collapse of the patient, the result of rupture of the bowel and escape of the contents into the peritoneal cavity. Pain as a rule is more or less constant, and is a most troublesome symptom. There is general but no localised tenderness of the abdomen on pressure. Usually there is constipation; occasionally diarrhœa. The temperature may reach $103^{\circ} \mathrm{F}$; generally it is but slightly above normal. The pulse is markedly increased in frequency, averaging from 100 to 120 . The tongue is usually red and irritable. Sometimes there is retention of urine without apparent cause, which is most probably reflex. There is no pain on voiding urine, unless the bladder has become attached to the gut by inflammatory adhesions.

The treatment is complete rest, with bland, easily digested food. Opiates are very essential; they must, however, be judiciously employed.

Montague-street, Russell-square.

West Norfork and Lynn Hospital.-The annual meeting of the governors of this institution was held on the 16th inst., when it was reported that the total number of patients who had received treatment in 1885 was 2437, against 2378 in 1884 . Dr. Lowe, who had for some years acted as consulting surgeon to the institution, having left the town, it was unanimously resolved that he be elected a vice-president of the hospital. The financial state of the charity is not satisfactory, the expenditure having during the past year somewhat exceeded the ordinary income.

Astley Cooper Prize.-The next triennial prize of $£ 300$ will be awarded to the author of the best essay or treatise on the Origin, Anatomy, Results, and Treatment of Tubercular Diseases of Bones and Joints. Essays are to be sent to Guy's Hospital on or before Jan. 1st, 1889, addressed to the physicians and surgeons of that institution.

\section{ON PHIMOSIS IN INFANCY.} BY GEOFFREY HETT M.D.

$M r$ excuse for submitting the following observations on this subject to the consideration of the profession is that my experience leads me to think that phimosis is a morbid condition which is not infrequently overlooked. Its persistence is the cause of much unnecessary suffering among children, and a neurotic habit is often induced which, in some instances, is never shaken off, but continues to exercise a prejudicial effect upon the usefulness and happiness of a considerable number of men during the whole of their lives. It would be advantageous if the following rule were adopted by all those taking charge of midwifery cases: to examine every male child within a few days of birth, and, if the prepuce cannot be retracted by the exertion of a moderate amount of force, to perform circumcision on or about the eighth day of life. The advocacy of such a rule will appear superfluous to many members of the profession, particularly to those who have had special opportunities of observing the diseases of children. That it is, however, not accepted, or, if theoretically accepted, not acted upon by numerous practitioners of midwifery, is suffciently proved by the frequency with which it is necessary to perform the operation in later life. Complete retraction of the prepuce is necessary in order to prevent the retention under it of the secretion of the numerous sebaceous glands in the mucous membrane of the cervix and glans penis (glandulæ Tysonii). The accumulation of this sebaceous matter, acting as a peripheral irritant through the internal pudic nerves, may, and often does, cause central mischief more or less grave according to the constitution of the child and the amount of local irritation. If the preputial opening be so small as to interfere with the easy passage of urine, the condition will be aggravated by some of this fluid being forced under the prepuce and increasing the congestion of the mucous membrane. The injury resulting from this cause may be productive of nothing more than slight peevishness of temper; but, on the other hand, may give rise to convulsive attacks terminating fatally, and, of course, to any effect intermediate between these extremes. I feel sure that many an unfortunate little boy is credited with bad temper and punished for naughtiness whose irritability is due to neglected phimosis, and consequently entirely beyond his own control. There is also much reason for thinking that the habit of masturbation is frequently led up to by a morbidly excitable condition of the sexual organs due to the same cause. Should no symptoms arise sufficiently severe to call attention to phimosis, and the child grow up to manhood with the defect unremedied, the liability to venereal disease must be largely enhanced by the impossibility of effectual ablution of the penis. The operation of circumcision is, in infancy, almost entirely free from risk if ordinary care be exercised. The only objection to it of which I am aware is the æsthetic one, and this cannot have much force in a clothes-wearing community, especially when the advantages derived from it are fully considered. Circumcision may be performed by seizing the extremity of the prepuce between the finger and thumb of the left hand, drawing it well forwards so that the outline of the glands can be clearly seen through the integument of the penis, and slicing it off diagonally downwards and forwards just in front of the glands with a sharp scalpel. The mucous membrane, which will be found still embracing the glands, should be split along the dorsum quite up to the cervix, turned back, and retained in position by a narrow strip of dry lint wrapped firmly three or four times round the penis. No sutures are necessary. The lint becomes saturated with blood, and, when this is dry, remains in position for from two to four days. On its removal the wound will generally be found completely healed, but, if any portion of it be granulating, it only requires the application of a little carbolised oil four or five times a day. I have never seen a case in which the dry lint failed to prevent any excessive hæmorrhage. The eighth day of life is a suitable time for the operation, as the organism of the child has by then become accommodated to its new environment. Inverness-terrace. 